\title{
Un mapa colaborativo para documentar y difundir los sistemas de regadíos históricos de Granada y Almería
}

El mapa colaborativo de regadíos históricos es una iniciativa que nace en 2015 desde el Laboratorio de Arqueología Biocultural (MEMOLab) de la Universidad de Granada para la visibilización de estos espacios productivos y las comunidades de regantes que los gestionan. Es una labor de documentación y puesta en valor en la que es fundamental la participación ciudadana, resaltando la implicación de las escuelas e institutos. Hasta la fecha cuenta con 585 acequias digitalizadas y 834 espacios de regadío localizados. Sin embargo, en palabras de sus creadores, "se trata de un proyecto en construcción, que espera ir perfeccionándose hasta llegar a ser un referente para el conocimiento y difusión de los regadíos históricos". Por el momento se ha centrado en las provincias de Granada y Almería, que concentran la gran mayoría de estos espacios.

José M. ${ }^{a}$ Martín Civantos | Dpto. de Historia Medieval y CCTTHH, Universidad de Granada

Maurizio Toscano | Oficina Europea FECYT (Fundación Española para la Ciencia y la Tecnología)

M. ${ }^{a}$ Teresa Bonet García | Arqueoandalusí, Arqueología y Patrimonio S.L.

Elena Correa Jiménez | Laboratorio de Arqueología Biocultural (MEMOLab), Universidad de Granada

URL de la contribución <http://www.iaph.es/revistaph/index.php/revistaph/article/view/5060>

\section{Origen y justificación}

Los sistemas históricos de regadío son agrosistemas de interés socioeconómico, ambiental y cultural que han creado paisajes de gran belleza y han dotado de identidad a los territorios donde se ubican. Son territorios modelados a lo largo de siglos de historia de coevolución entre el ser humano y la naturaleza. Sus valores patrimoniales, ambientales, agronómicos, identitarios y estéticos son cada vez más reconocidos a nivel internacional.

Se desconoce su extensión y el número exacto de comunidades de regantes históricas y tradicionales que gestionan estos espacios. Podemos decir que solo en las provincias de Granada y Almería hay, al menos, unas 550 comunidades de regantes y más de 830 espacios de riego históricos y tradicionales, que suponen casi 200.000 hectáreas de regadío, más de 24.000 km de acequias y más de 90.000 regantes. La mayor parte de las comunidades ha sobrevivido durante siglos, mostrando una gran capacidad de resiliencia, pero actualmente se encuentran en grave riesgo de desaparición. Se ven marginadas por la crisis de la agricultura tradicional, la presión urbana y por los efectos de la Directiva Marco Europea del Agua y la Ley de Aguas de Andalucía.

En el Laboratorio de Arqueología Biocultural (MEMOLab) de la Universidad de Granada consideramos fundamental el conocimiento y la difusión de los sistemas de regadío histórico como elementos patrimoniales y paisajísticos. Con estas premisas se planteó la creación del mapa colaborativo de regadíos históricos de Granada y Almería que los aglutinara y permitiera su visualización. Este se llevó a cabo en el marco del proyecto europeo MEMOLA (MEditerranean MOuntainous LAndscapes) y con la ayuda de la Asociación de Comunidades de Regantes Históricas y Tradicionales de Andalucía. La relevancia de la iniciativa fue reconocida también por la Fundación Española para la Ciencia y la Tecnología, del Ministerio de Ciencia e Innovación, que co-financió en dos ocasiones su desarrollo y ampliación. En concreto, a través de la convocatoria 2015, del programa de Cultura científica, se financió el proyecto Acequias. Programa de ciencia participativa basado en el estudio de los valores culturales y ambientales de los sistemas históricos de regadío de Granada y Almería (FCT-15- 
9814) donde pudimos arrancar la plataforma y el mapa colaborativo. Sucesivamente, en la convocatoria 2019, con el programa de Vocaciones científicas, se financió el proyecto Aprender a ser científic@s con el regadío histórico (FCT-19-15217), que ha permitido dar a conocer los sistemas históricos de regadío a la comunidad educativa de diferentes comarcas rurales de la provincia de Granada (Valle de Lecrín, Altiplano, Guadix y La Alpujarra). El alumnado ha podido estudiar y analizar los sistemas de regadío histórico de sus municipios con la creación de fichas hidráulicas y audiovisuales, que han sido compartidas en la web.

\section{Objetivos}

El objetivo del mapa colaborativo es fomentar el conocimiento de los sistemas históricos de regadío implicando en su realización tanto a los propios agricultores y regantes, como a la comunidad educativa y a la población en general. Pretendemos también sensibilizar sobre su importancia en nuestros paisajes y consideramos que con la impactante visualización del mapa, que permite mirar al conjunto de los sistemas de regadío histórico como fenómeno espacial de ingente extensión, contribuimos a revalorizar la importancia del trabajo agrícola.

\section{Metodología}

La realización del mapa supuso un largo y elaborado esfuerzo de búsqueda de información y de contacto con las comunidades de regantes. En torno a los sistemas históricos de regadío existe un enorme desconocimiento, no solo desde la administración, sino también desde la propia academia. Este desconocimiento proviene de su propia complejidad, y de su enorme grado de autonomía en la gestión comunal del agua y en la resolución de conflictos derivados de ello.

Para llevar a cabo el mapa se realizó un vaciado de la documentación disponible, y se contactó con numerosas comunidades para recabar información complementaria e intentar obtener documentación. Las comunidades de regantes basan sus conocimientos y sus prácticas fundamentalmente en la tradición oral. Esto dificultó enormemente la tarea, pero forma parte de los mecanismos y estrategias históricas de las comunidades para defender sus usos y sus derechos.
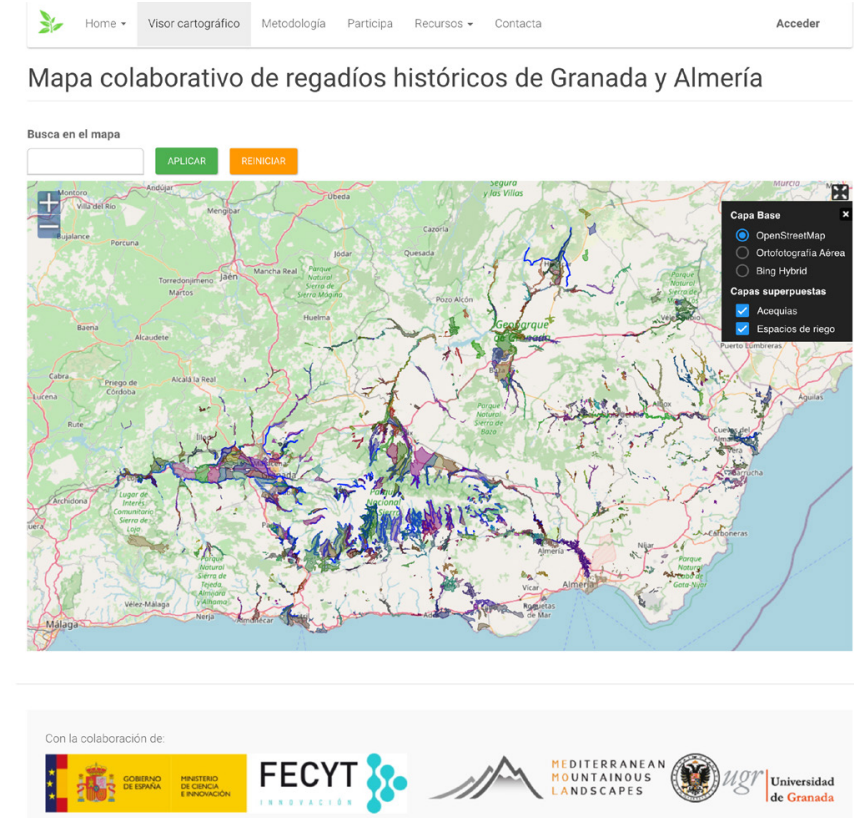

Visor cartográfico colaborativo de las acequias y espacios de riego históricos y tradicionales en las provincias de Granada y Almería

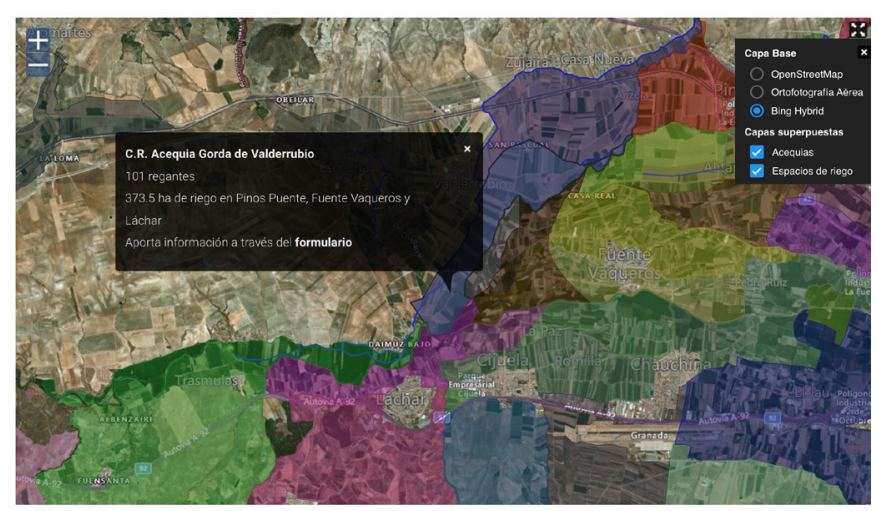

Detalle de la consulta sobre una acequia representada en el mapa

El mapa tiene un carácter colaborativo no solo por cómo arrancó, sino también porque pretendemos que los usuarios continúen participando y nos envíen información, correcciones o comentarios que contribuyan a mejorarlo. Para ello cuenta con una pestaña de contacto y, sobre todo, con otra de participación donde es posible enviar información de interés, así como subir y enviar documentos e imágenes y dibujar directamente sobre la fotografía aérea para delimitar espacios de riego, trazar acequias o señalar elementos importantes de estos sistemas que puedan estar equivocados o que no hayan sido recogidos. 


\section{Conclusiones}

El mapa colaborativo de regadío histórico lleva en funcionamiento desde el 2015, cuenta con 585 acequias digitalizadas y 834 espacios de regadío, que son, probablemente, una ínfima parte de aquellos que aún hoy existen y que no están documentados. Las visitas a la web (4.415 usuarios únicos y más de 15.000 páginas visitadas desde su lanzamiento) demuestran el interés que esta información suscita tanto a nivel nacional como a nivel internacional (el $45 \%$ de las visitas son desde el exterior).

La última ampliación de la plataforma ha venido de parte de los colegios e institutos de las diferentes comarcas granadinas que han participado en el proyecto de vocaciones científicas. De esta forma, hemos incorporado una parte fundamental de la ciudadanía, a la que debemos hacer partícipe de la conservación y del mantenimiento de estos sistemas.
Desde el MEMOLab continuamos trabajando para mejorar la plataforma y ampliar el conocimiento de estos sistemas de regadío histórico. La importancia del conocimiento de estos sistemas, de su forma, de su funcionamiento y de su gestión oral tradicional basada en los principios comunales, será primordial para la sostenibilidad futura de la actividad agraria.

Instituto

Todo IES Valle de Lecrin (Durcal) $\quad$ IES La Alpujarra (Orgiva) IES Padre Poveda (Guadix) IES Marquesado del Zenete (Alquife)

Clase

\begin{tabular}{ll|l|l|} 
Todo & Primero de la ESO Segundo de la ESO & Tercero de la ESO & Primero de Bachillerato
\end{tabular}

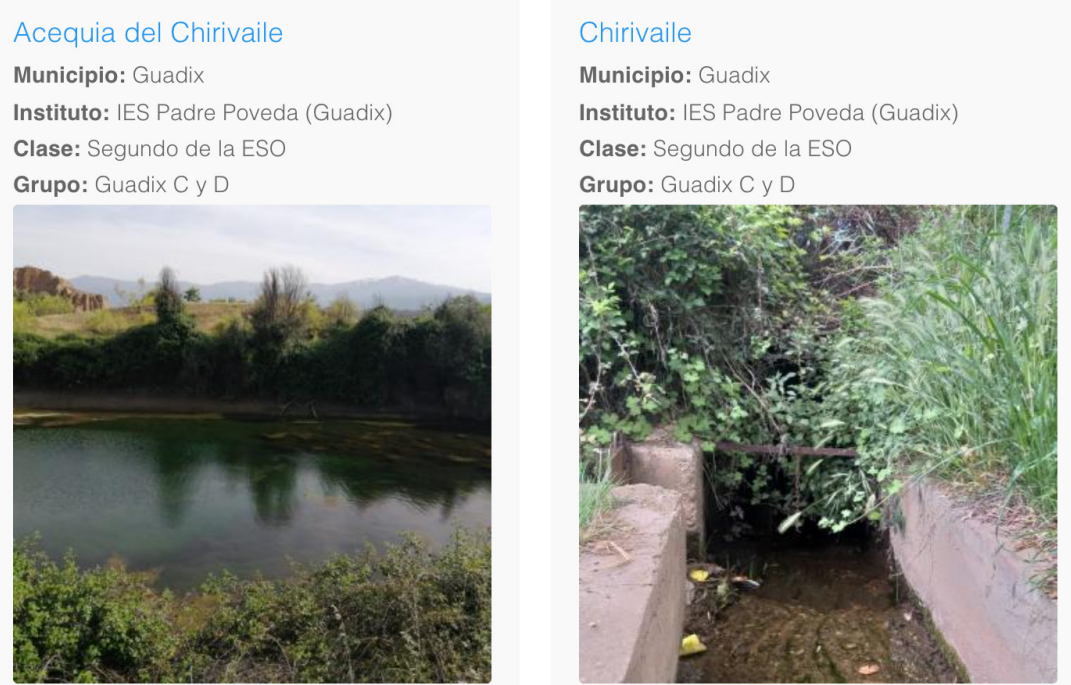

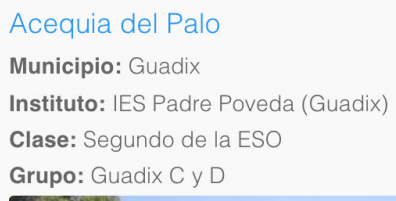

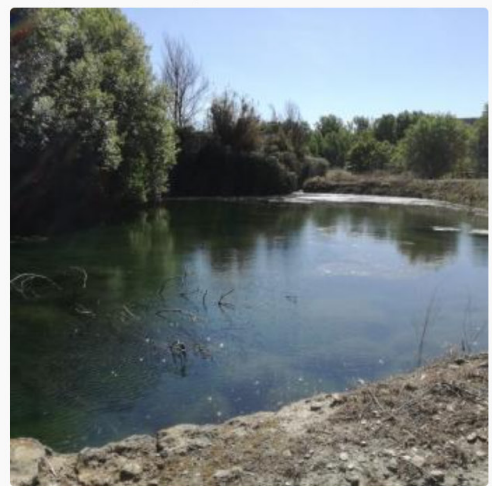

Algunas de las fichas hidráulicas rellenadas por los alumnos involucrados en el proyecto Aprender a ser científic@s con el regadío histórico (FCT-19-15217) 